\title{
DISTRIBUTION AND SPECTRUM OF HAEMATOLOGICAL DISORDERS ON BONE MARROW STUDY
}

\author{
Anu Mangoch ${ }^{1}$,Kuldeep K. Koul ${ }^{2}$
}

${ }^{1}$ Resident, Department of Pathology, Government Medical College, Jammu, J and K.

2Professor and HOD, Department of Pathology, Government Medical College, Jammu, J and K.

\section{BACKGROUND}

ABSTRACT

Haematological disorders include a wide range of diseases ranging from anaemias to haematological malignancies. Examination of the marrow is critically important in the study and management of wide variety of haematological disorders. Bone marrow examination is safe and useful test in reaching the final diagnosis.

\section{MATERIALS AND METHODS}

This descriptive study was carried out in the Postgraduate Department of Pathology, Government Medical College, Jammu, India over a period of five years (November 2011 to October 2016). 1600 cases were diagnosed by bone marrow aspiration. Complete blood count, peripheral smear and bone marrow study were performed in all cases. Those with inconclusive report due to inadequate sample were dropped.

\section{RESULTS}

Bone marrow aspiration from 1600 patients were analysed. The male-to-female ratio was 1.3: 1 with maximum number of cases in the age group of $11-20$ years and $40 \%$ of the cases were in the paediatric age group. Nutritional anaemia contributed to the most common haematological disorders. Among them, the incidence of megaloblastic anaemia was highest (50\%). The other haematological disorders were ITP (5\%), Aplastic anaemia (2.50\%), Haemolytic anaemia (0.62\%), Haemoparasites (0.62\%), Hypersplenism (0.37\%), Hypereosinophilic syndrome (0.31\%), Haemophagocytic syndrome (0.25\%), Congenital dyserythropoietic anaemia (0.18\%), Thalassemia $(0.12 \%)$, Sickle cell disease $(0.06 \%)$ and Niemann's pick disease $(0.06 \%)$. In Malignant haematological disorders, the most common was found to be leukaemia $(15.75 \%)$. Amongst these, acute lymphoblastic leukaemia (6.25\%) was more common. Others were Multiple myeloma (1.62\%), MDS (0.5\%), Waldenstrom's macroglobulinaemia $(0.25 \%)$, lymphomas $(0.25 \%)$ and CMML $(0.12 \%)$. One case of myeloproliferative variant of hypereosinophilic syndrome $(0.06 \%)$ was diagnosed during the study period. Bone marrow mets $(0.37 \%)$ were observed to be the most important cause of secondary bone marrow involvement by a non-haematological malignancy.

\section{CONCLUSION}

Bone marrow study plays a very important role not only in determining the cause of disease, but also helps in establishing a definitive diagnosis. It is one of the most common and safe procedures done routinely on outpatient basis.

\section{KEY WORDS}

Bone Marrow Aspiration, Bone Marrow Biopsy, Diagnostic Role, Haematological Disorders.

HOW TO CITE THIS ARTICLE: Mangoch A, Koul KK. Distribution and spectrum of haematological disorders on bone marrow study. J. Evolution Med. Dent. Sci. 2018;7(20):2475-2480, DOI: 10.14260/jemds/2018/557

\section{BACKGROUND}

Sir William Harvey described blood as "fountain of life and the primary seat of the soul. The marrow of our bones is the seedbed of our blood." Careful assessment of the blood elements is often the first step in assessment of haematological function and diagnosis. Bone marrow examination has been the corner stone of haematology practice, since its introduction into routine clinical use in the 1940s. ${ }^{1}$ Bone marrow aspiration gives a more complete picture of the reaction of the haemopoietic tissue to anaemia than can be gained from peripheral blood smear alone. ${ }^{2}$ The definitive diagnosis of primary and metastatic haematopoietic malignancies requires microscopic

'Financial or Other Competing Interest': None.

Submission 31-03-2018, Peer Review 25-04-2018,

Acceptance 02-05-2018, Published 14-05-2018.

Corresponding Author:

Dr. Anu Mangoch,

H. No. 180/B, Greater Jammu Colony,

Bye Pass Kunjwani, Jammu,

J and $K$, India.

E-mail: dranumangoch87@gmail.com

DOI: $10.14260 /$ jemds $/ 2018 / 557$

\section{(c) $($ ) $९$}

examination of marrow aspiration or trephine biopsy, because it provides direct evidence of the presence and the nature of disease. The bone marrow is involved in a variety of haematological and non-haematological disorders. The haematological diseases include leukaemias, lymphomas, nutritional deficiency diseases like iron deficiency anaemia, megaloblastic anaemia, anaemia of chronic disorders and hypoplastic anaemia. The bone marrow is also frequently involved in granulomatous disorders and metastatic disorders. Diagnosis and management of many haematologic diseases depends on examination of the bone marrow, which usually involves two separate specimens: a cytologic and a histologic preparation. While cytologic preparation of bone marrow obtained by aspiration allows excellent visualisation of cell morphology, the histological preparation of bone marrow allows optimal evaluation of cellularity, fibrosis or infiltrative disease. ${ }^{3}$ The aspirate films are more sensitive for studying differential cell count and cytomorphology. When marrow aspiration leads to "dry tap," in such situations evaluation of bone marrow cellularity and abnormal architecture patterns and detection of structures other than the haematopoietic cells within the marrow are best achieved by bone marrow biopsy. ${ }^{1}$ The present study is being 
conducted to study the distribution and spectrum of haematological disorders.

\section{MATERIALS AND METHODS}

This descriptive study was done in the Postgraduate Department of Pathology, Government Medical College Jammu, India for a period of five years (November 2011 to October 2016). A total of 1600 cases were included in this study. Patients with history and clinical feature like pallor, fatigue, bleeding in the form of bruise or petechiae, persistent fever, bone or joint pains, organomegaly and lymphadenopathy were taken up for detailed haematological evaluation. Patients referred from district hospital and other health care centres of our state were also included in this study. Those with inconclusive report due to inadequate sample were dropped from the study. Complete blood count including haemoglobin, total and differential leucocyte count and platelet count were performed using automated haematology analyser. Peripheral smear examination was done after Leishman stain. Bone marrow aspirate smears obtained were stained with May-Grunwald-Giemsa and Perls' Prussian blue stain. Bone marrow trephine biopsy was done in selected patients where marrow aspiration yielded blood only (dry tap). Haematoxylin and eosin and reticulin stains were used when needed. Then data was analysed manually by frequency and percentage.

\section{RESULTS}

A total number of 1600 patients were included in this study. Among these 896 (56\%) were males and 704 (44\%) were females with sex ratio of 1.3: 1 . The patient distribution into different age groups was studied. The maximum number of patients (29.5\%) of haematological disorders who underwent bone marrow examination was in the age group of $11-20$ years. Haematological disorders were found to affect adults $(60 \%)$ more than paediatric age group (below or equal to 18 years of age) $(40 \%)$. (Table 1 ) shows the age distribution. Patients presented with overlapping clinical features (Table 2). Generalised weakness (76\%) and fever (40\%) were the most common presenting symptom. Pallor (90\%) was the most frequently observed sign.

\begin{tabular}{|c|c|c|}
\hline Age Group (in yrs.) & No. of Patients & Percentage (\%) \\
\hline $0-10$ & 269 & 16.7 \\
\hline $11-20$ & 474 & 29.5 \\
\hline $21-30$ & 236 & 14.7 \\
\hline $31-40$ & 186 & 11.6 \\
\hline $41-50$ & 178 & 11 \\
\hline $51-60$ & 135 & 9 \\
\hline$>60$ & 122 & 7.6 \\
\hline Total & $\mathbf{1 6 0 0}$ & $\mathbf{1 0 0}$ \\
\hline Table 1. Age Wise Distribution of Haematological \\
Disorders \\
\hline
\end{tabular}

Bone marrow examination findings are given in (Table 3). Out of 1600 cases detected during the said period, majority cases were nutritional deficiency anaemias. Among them, the incidence of megaloblastic anaemia was highest followed by dual deficiency anaemia and iron deficiency anaemia. In malignant haematological disorders, the most common was found to be leukaemia (Fig. 1) followed by multiple myeloma (Fig. 2). Other haematological disorders diagnosed were Hypereosinophilic syndrome, Haemophagocytic syndrome, congenital dyserythropoietic anaemia, thalassemia, sickle cell disease with haemolytic crisis (Fig. 3), Niemann's pick disease (Fig. 4). One case of myeloproliferative variant of hypereosinophilic syndrome was diagnosed during the study period (Fig. 5). Bone marrow mets were observed to be the most important cause of secondary bone marrow involvement by a non-haematological malignancy. Out of 6 cases of metastatic deposits, 3 cases were of adenocarcinoma lung (Fig. 6), 2 cases were of adenocarcinoma prostate and 1 case was of neuroblastoma. Distribution of subtypes of haematological and non-haematological malignancies are given in (Table 4).

\begin{tabular}{|c|c|c|}
\hline Clinical Presentation & Total No. & Percentage (\%) \\
\hline Pallor & 1440 & 90 \\
\hline Weakness & 1216 & 76 \\
\hline Fever & 640 & 40 \\
\hline Bone pains & 170 & 10.6 \\
\hline Weight loss & 288 & 18 \\
\hline Bleeding & 315 & 20 \\
\hline Lymphadenopathy & 160 & 10 \\
\hline Organomegaly & 360 & 23 \\
\hline
\end{tabular}

Table 2. Clinical Presentation of Haematological Disorders

\begin{tabular}{|c|c|c|}
\hline Haematological Diagnosis & No. & Percentage (\%) \\
\hline Megaloblastic anaemia & 800 & 50 \\
\hline Dual deficiency anaemia & 300 & 18.75 \\
\hline $\begin{array}{c}\text { Acute lymphoblastic leukaemia } \\
\text { (ALL) }\end{array}$ & 100 & 6.25 \\
\hline Acute myeloid leukaemia (AML) & 90 & 5.62 \\
\hline $\begin{array}{l}\text { Idiopathic thrombocytopenic } \\
\text { purpura }\end{array}$ & 80 & 5.0 \\
\hline Aplastic/ hypoplastic anaemia & 40 & 2.50 \\
\hline $\begin{array}{l}\text { Chronic myelogenous leukaemia } \\
\text { (CML) }\end{array}$ & 40 & 2.5 \\
\hline Iron deficiency anaemia & 36 & 2.25 \\
\hline Multiple myeloma (MM) & 26 & 1.62 \\
\hline $\begin{array}{l}\text { Chronic lymphocytic leukaemia } \\
\text { (CLL) }\end{array}$ & 20 & 1.25 \\
\hline Haemolytic anaemia & 10 & 0.625 \\
\hline Haemoparasites & 10 & 0.62 \\
\hline Myelodysplastic syndrome (MDS) & 08 & 0.5 \\
\hline Bone marrow mets & 06 & 0.37 \\
\hline Hypersplenism & 06 & 0.37 \\
\hline Hypereosinophilic syndrome & 05 & 0.31 \\
\hline Lymphoma & 04 & 0.25 \\
\hline $\begin{array}{c}\text { Waldenstrom's } \\
\text { macroglobulinaemia }\end{array}$ & 04 & 0.25 \\
\hline Haemophagocytic syndrome & 04 & 0.25 \\
\hline $\begin{array}{c}\text { Congenital dyserythropoietic } \\
\text { anaemia }\end{array}$ & 03 & 0.18 \\
\hline $\begin{array}{c}\text { Chronic myelomonocytic } \\
\text { leukaemia (CMML) }\end{array}$ & 02 & 0.12 \\
\hline Thalassemia & 02 & 0.12 \\
\hline Infective pathology & 02 & 0.12 \\
\hline $\begin{array}{l}\text { Sickle cell disease with } \\
\text { haemolytic crisis }\end{array}$ & 01 & 0.06 \\
\hline Niemann's pick disease & 01 & 0.06 \\
\hline $\begin{array}{l}\text { Myeloproliferative variant of } \\
\text { hypereosinophilic syndrome }\end{array}$ & 01 & 0.06 \\
\hline Total & 1600 & 100 \\
\hline
\end{tabular}




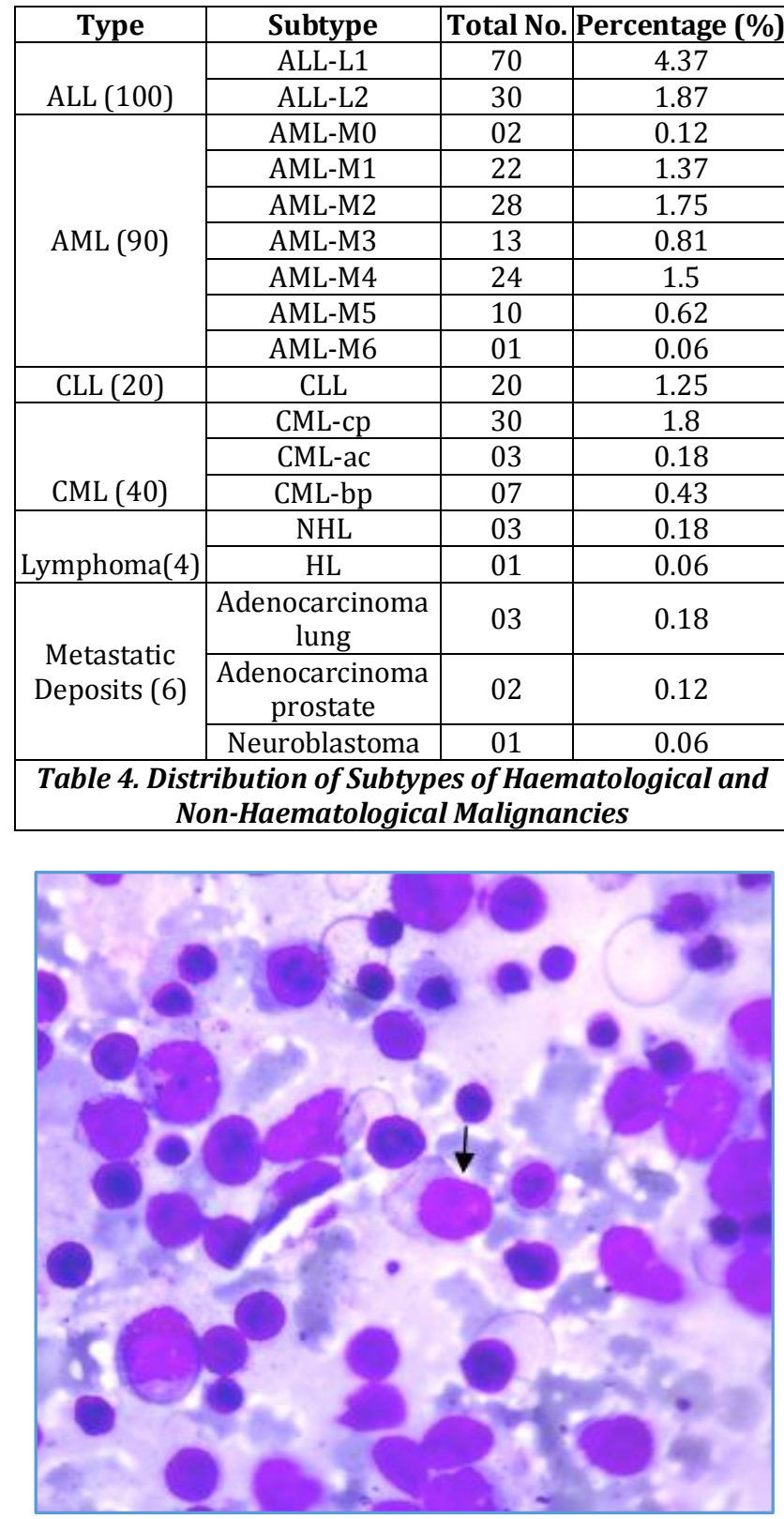

Figure 1. BMA showing Erythroid Precursors with some Myeloblasts and one Myeloblast with Auer Rod ( $\uparrow$ ) in AML$M_{6}$ (MGG 100X)

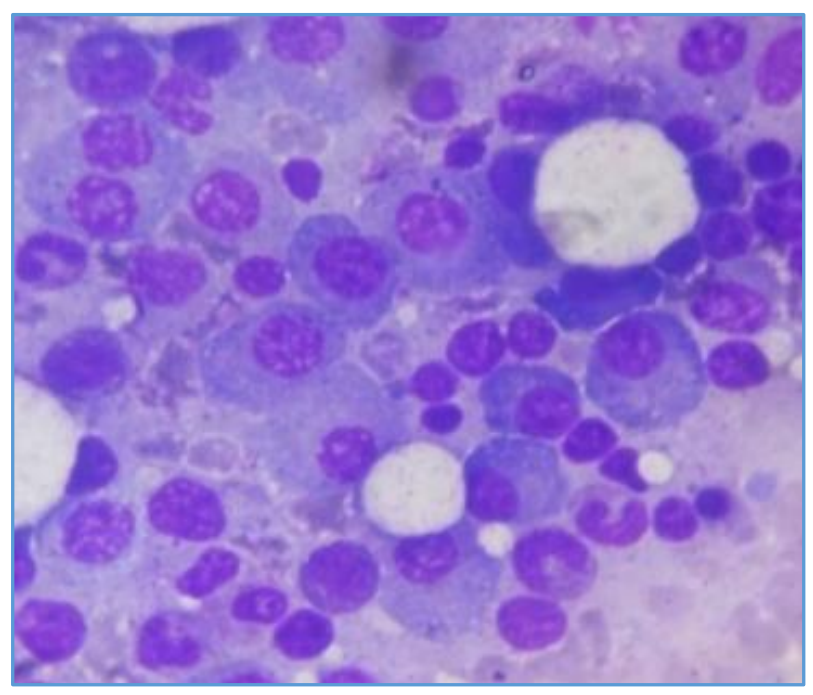

Figure 2. BMA showing Plasma Cells in MM (MGG 100X)

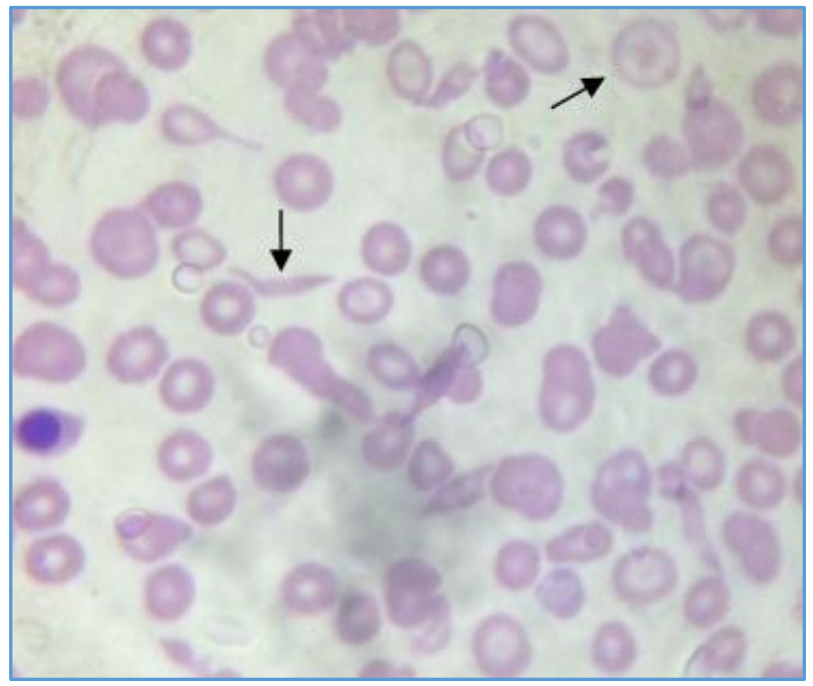

Figure 3a. PBF showing Nucleated Red Cell, Target Cells ( $\uparrow$ and Sickle Cells ( $\uparrow$ ) in Sickle Cell Disease with Haemolytic Crisis (Leishman's Stain 100x)

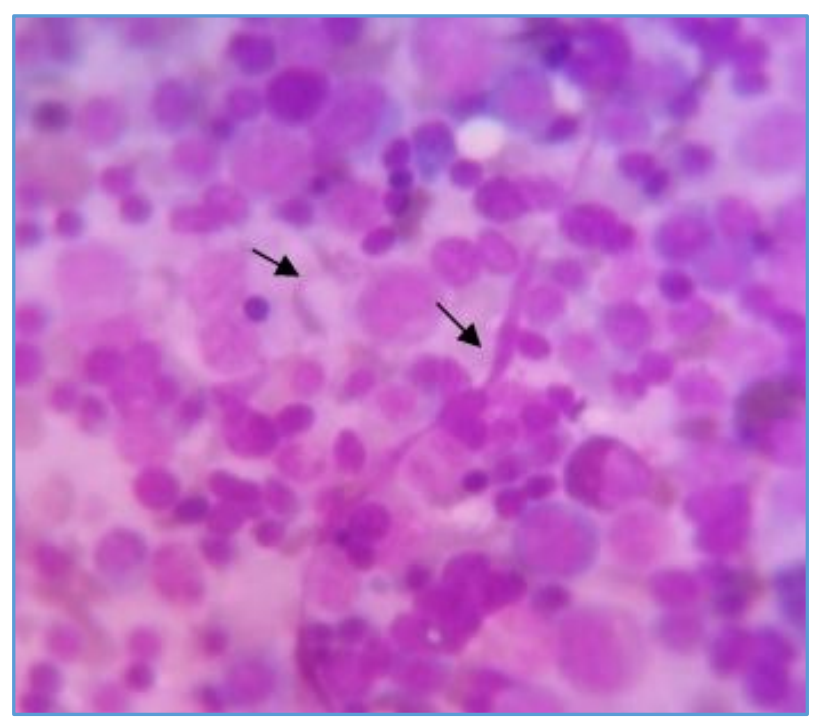

Figure 3b. BMA showing Abnormal Elongated Sickle Cells ( $\uparrow$ ) in Sickle Cell Disease (MGG 100X)

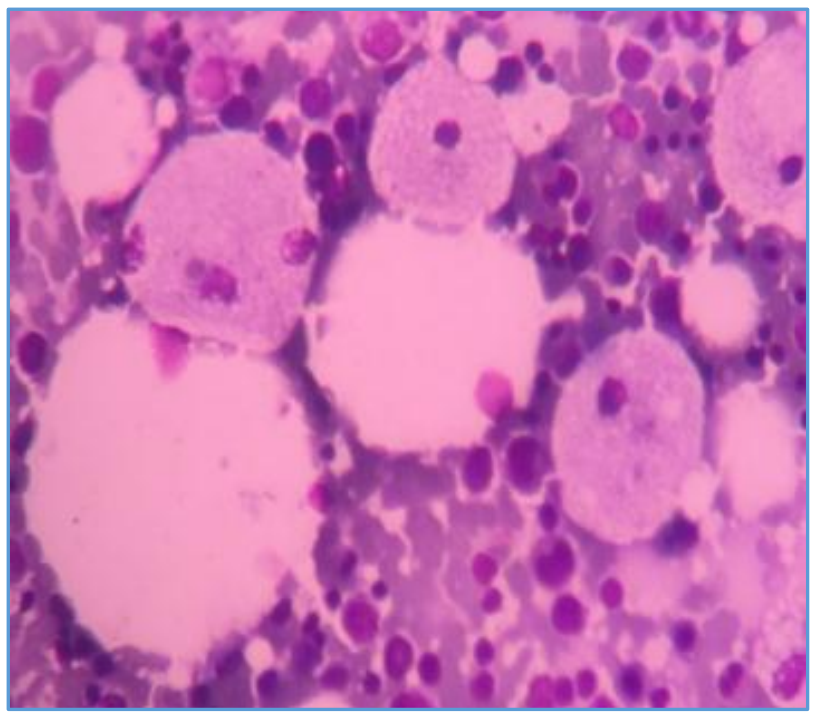

Figure 4. BMA showing Niemann-Pick Cells in Niemann's Pick Disease (MGG40X) 


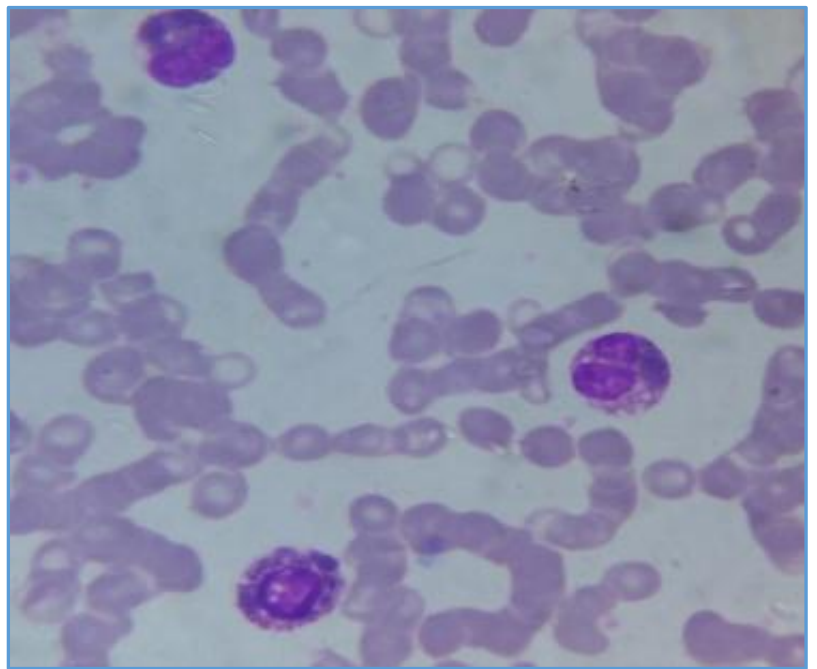

Figure 5a. PBF Showing Eosinophilia with Eosinophilic Myelocyte in Myeloproliferative Variant of

Hypereosinophilic Syndrome (PDGFRA and FIP 1 L 1+ve) Leishman's Stain 100X

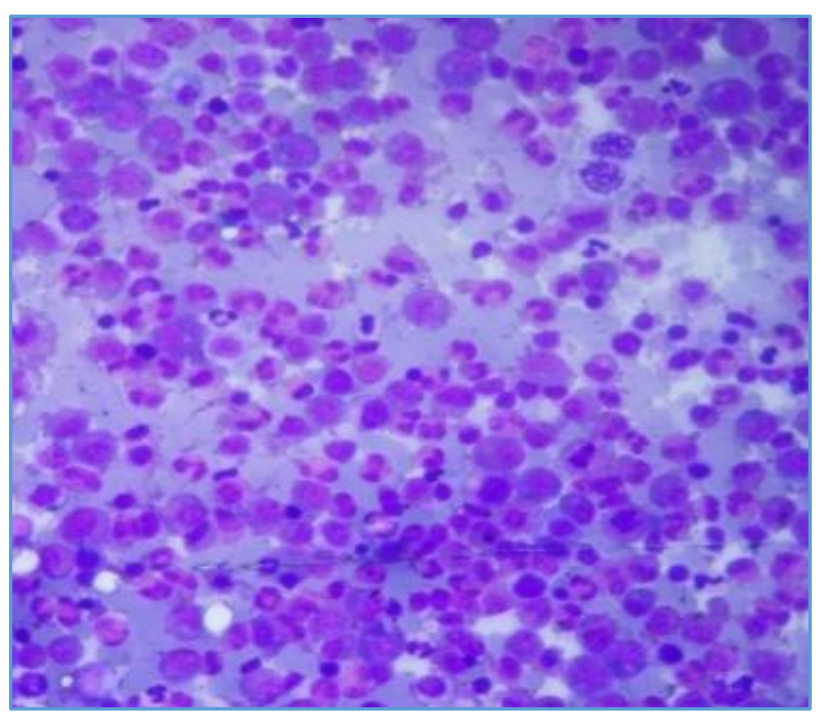

Figure 5b. BMA showing Increase in Eosinophils and Eosinophilic Precursors in the Same Patient (MGG 40X)

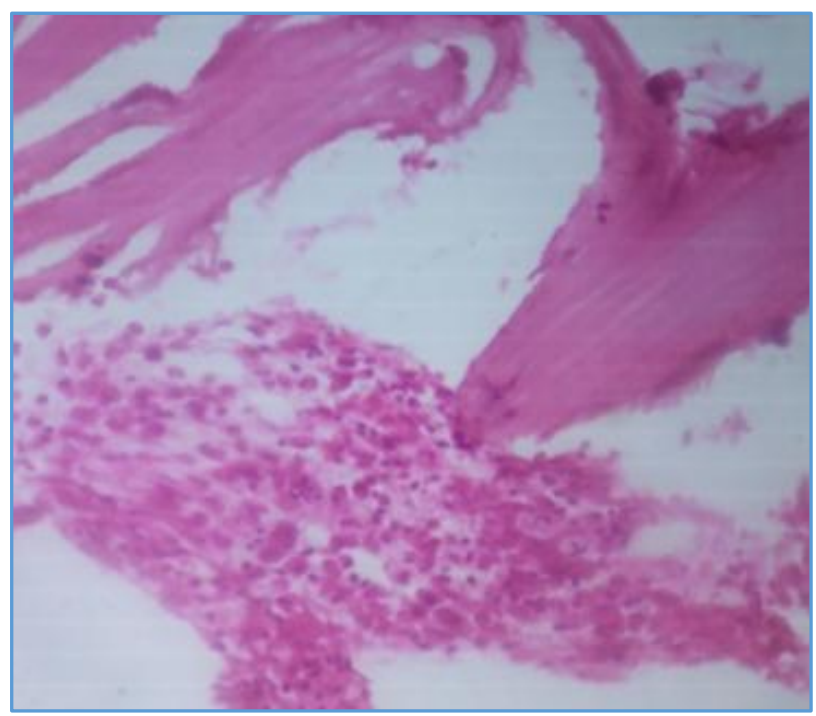

Figure 5c. BM Trephine Biopsy showing Infiltration of Eosinophils and their Precursors in the Same Patient (H and $E$ 10X)

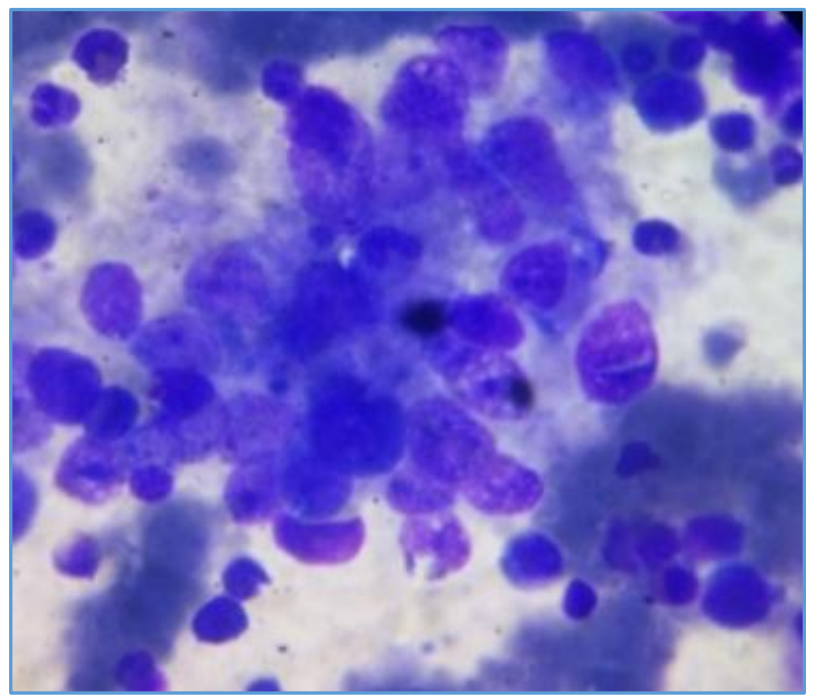

Figure 6. BMA showing Metastatic Deposits of Adenocarcinoma (MGG 100X)

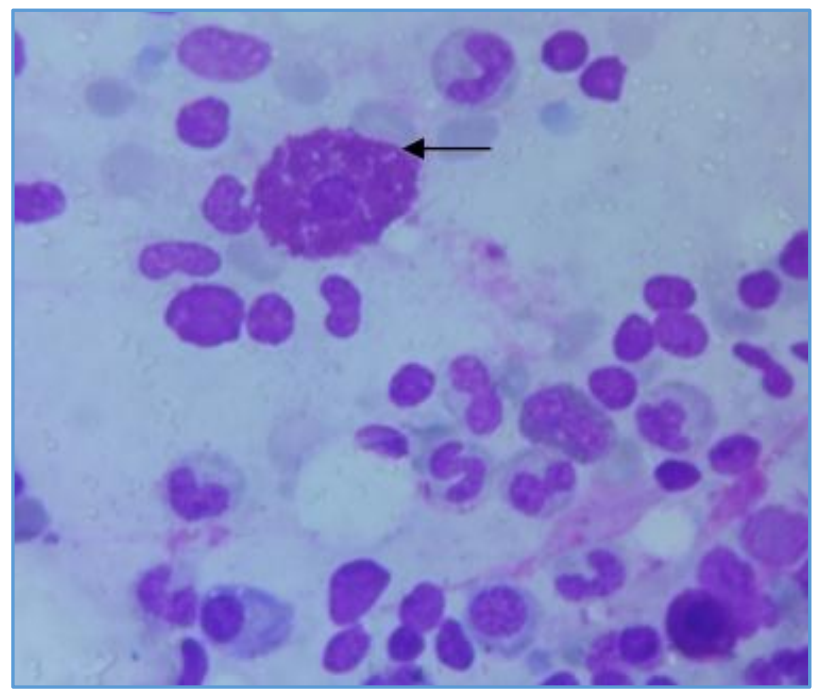

Figure 7. BMA showing Mast (†) Cells, Lymphocytes and Plasma Cells in Waldenstrom's Macroglobulinaemia (MGG100X)

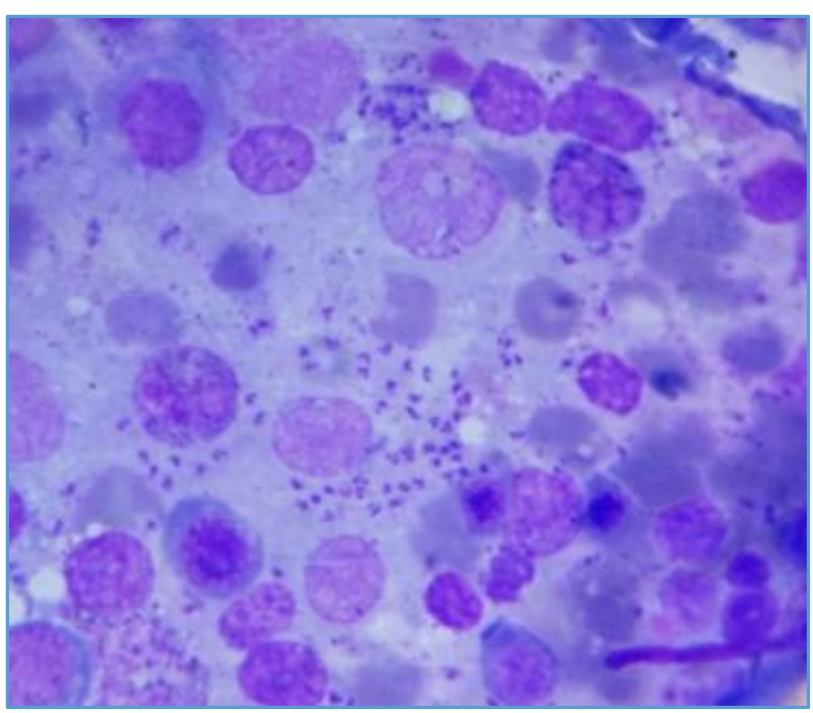

Figure 8. BMA showing LD Bodies in Visceral Leishmaniasis (MGG 100X) 


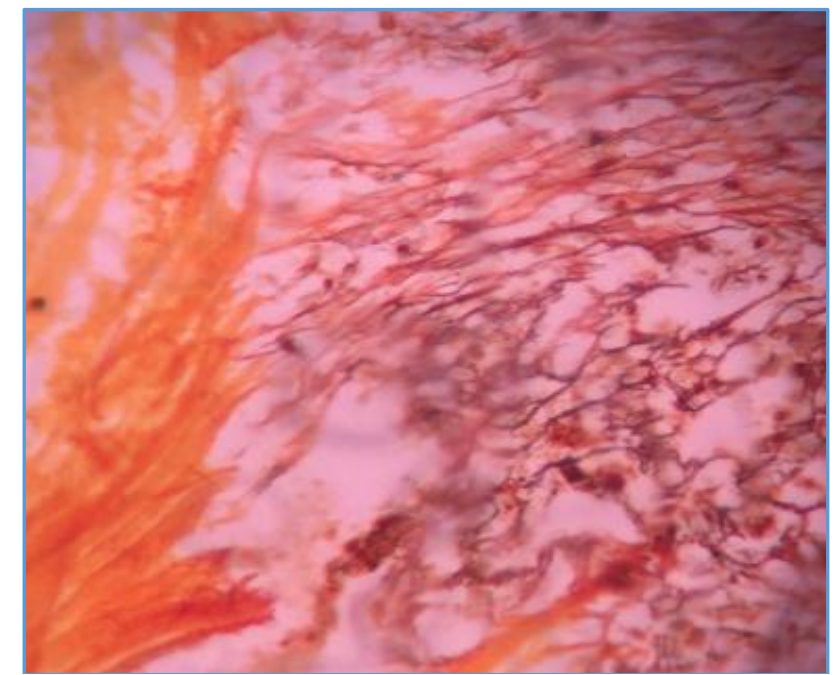

Figure 9. BMB showing Increased Reticulin Fibre Density and Thickness in Myelofibrosis (Reticulin Stain 40X)

\section{DISCUSSION}

Bone marrow aspiration is an important and useful clinical and laboratory investigation for the study of various haematological disorders. It is one of the most common and safe procedure and can be done routinely on an outpatient basis. The sex distribution of haematological disorders were recorded and overall more male cases were found 896 (56\%) as compared to females 704 (44\%). Male: Female ratio was found to be 1.3: 1 . This observation was comparable to that in the study done by Thiyagarrajan $\mathrm{P}$ et al. ${ }^{4}$

In our study, the maximum number of cases were recorded among 11 - 20 years of age group 474 (29.6\%), whereas less number of cases were seen in older age group i.e. > 60 years of age 122 (7.6\%). Similar findings were seen in study conducted by Kibria SG et al. ${ }^{5}$ However, Shastry SM et $\mathrm{al}^{6}$ and Anjum MU et $\mathrm{al}^{7}$ reported the maximum number of cases among 21 - 30 years of age group. The occurrence of pallor, fever, LAP, organomegaly, bone pains and bleeding manifestation in a particular haematological disorder as diagnosed by BMA were similar to study done by Dapus DO and James D. 8 These findings contributed to the request for bone marrow study as they are known to be related to haematologic diseases, particularly when found in combination in a patient. In our study, nutritional deficiency anaemias were the most common haematological disorders. Among these, megaloblastic anaemia contributed to the maximum number of cases. These findings correlate with study done by Jha et $\mathrm{al}^{9}$ and Patel S et al. ${ }^{10}$ The second most common was dual deficiency anaemia followed by iron deficiency anaemia. But in a study done by Gayathri et al ${ }^{11}$ and Pudasaini $S$ et $\mathrm{al}^{12}$ they found that dual deficiency anaemia is least frequent than iron deficiency anaemia. This could be due to the fact that mostly iron deficiency anaemia is treated on an outpatient basis in our centre and bone marrow examination is not routinely done to confirm its diagnosis. One case of sickle cell disease with haemolytic crisis and two cases of thalassemia were diagnosed during the study period similar to study done by Shastry SM et al. ${ }^{6}$ Presence of sickle cells in the PBF pointed towards sickle cell disease and BMA showed hyperplastic marrow, erythroid hyperplasia with features of dyserythropoiesis and sickle cells. Blood smear is useful in the diagnosis of sickle cell disease, particularly if there is an urgent need for diagnosis and if the results of haemoglobin electrophoresis or high-performance liquid chromatography are not instantly available. ${ }^{13}$

Leukaemia was the most common malignant haematological disorder present in 252 cases followed by Multiple myeloma 26 cases, Waldenstrom's macroglobulinaemia 4 cases (Fig. 7), metastatic deposits 6 cases, lymphomas 4 cases and CMML 2 cases. Similar results have been reported in a study done by Khan $\mathrm{A}$ et al ${ }^{14}$ and Patel J and Popat VC ${ }^{15}$ who also reported leukaemia as the most common malignant haematological disorder. Acute leukaemias were found to be more common than chronic leukaemia similar to studies conducted by Al-Ghazaly J et al ${ }^{16}$ and Kulshrestha R et al. ${ }^{17}$ ALL was found to be more common than AML, similar to a study done by Dapus DO and James D ${ }^{8}$ and Anjum MU et al. ${ }^{7}$ Among chronic leukaemia, CML cases were more frequent than CLL cases. This observation was comparable to that of Patel J and Popat VC.15 Biopsy in two patients of CML showed increase in granulocytic series as well as megakaryocytes along with the presence of marrow fibrosis, thus giving the morphologic subtype (granulocytic and megakaryocytic subtype). Out of four cases of lymphoma, NHL cases were more frequent than HD similar to the study done by Troussard $\mathrm{X}$ et al. ${ }^{18}$ Among non-haematological disorders, myelophthisic anaemia, especially bone marrow mets were most common. Three cases were of adenocarcinoma lung, two cases were of adenocarcinoma prostate and one case was of neuroblastoma. One case of metastatic deposits of poorly differentiated adenocarcinoma lung was diagnosed on biopsy. Ozkalemkas et al in their study observed the most common non-haematological malignancy involving the bone marrow to be adenocarcinoma with the primary focus in stomach in 5 cases, prostrate in 3 cases and lung in 1 case. ${ }^{3}$ In our study, haemoparasite, i.e. Leishmania donovani (Fig. 8) causing kala-azar was reported in 10 cases. Majority of these patients were from the hilly areas. Haemoparasites can be a cause of haematological disorders and they should be specifically looked for while examining the bone marrow aspirate. There was one case of Niemann's pick disease. We found that bone marrow aspiration is helpful in making primary diagnosis of storage disease.

One rare case of myeloproliferative variant of hypereosinophilic syndrome (PDGFRA +ve and FIP1 L1 +ve) was diagnosed during the study period. Patient was being treated for heart ailments and was having eosinophilia (Rheumatic heart disease) and was sent to us for evaluation of sustained eosinophilia. In correlation with peripheral smear, bone marrow findings and after exclusion of secondary causes we diagnosed the case as myeloproliferative variant of hypereosinophilic syndrome as PDGFRA and FIP1 L1 fusion gene was positive. Bone marrow trephine biopsy was done in patients where marrow aspiration yielded blood only (dry tap). Marrow histological sections were examined for architecture, presence of foreign cells, marrow fibrosis, dyserythropoiesis and dysmegakaryopoiesis. Patients in whom bone marrow aspiration yielded scant material were diagnosed as aplastic anaemia on trephine biopsy. In patients where bone marrow aspiration yielded dry tap, marrow trephine biopsy revealed moderate-to-marked fibrosis with increased microvessel density, sinusoidal dilatation and increased atypical megakaryocytes. These cases were diagnosed as myelofibrosis (Fig. 9). Frisch et $\mathrm{al}^{19}$ have also observed that in 
the majority of cases myeloproliferative disorders, especially myelofibrosis may be recognised and classified by the initial bone marrow histology. Hence, the finding of a dry tap should never be dismissed as being due to faulty technique and always needs a bone marrow biopsy.

\section{CONCLUSION}

Bone marrow study plays a very important role not only in determining the cause of disease, but also helps in establishing a definitive diagnosis. Nutritional deficiency anaemias (particularly the megaloblastic anaemia) were the most common haematological disorders, thus it reflects the poor socio-economic and nutritional status of the society. The diagnosis of haematological disorders is achieved mainly by the examination of peripheral blood and bone marrow aspirate smears with trephine biopsies acting as a useful adjunct. However, a careful and detailed peripheral blood examination along with clinical information is still the cornerstone for suspecting a particular haematological disorder in most cases.

\section{REFERENCES}

[1] Ellman L. Bone marrow biopsy in the evaluation of lymphoma, carcinoma and granulomatous disorders. Am J Med 1976;60(1):1-7.

[2] Egesie OJ, Joseph DE, Egesie UG, et al. Epidemiology of anaemia necessitating bone marrow aspiration cytology in JOS. Niger Med J 2009;50(3):6-1.

[3] Ozkalemkas F, Ali R, Ozkocaman V, et al. The bone marrow aspirate and biopsy in the diagnosis of unsuspected non haematologic malignancy: a clinical study of 19 cases. Bio Medical Central Cancer 2005;5:144.

[4] Thiyagarrajan P, Suresh TN, Anjanappa R, et al. Bone marrow spectrum in a tertiary care hospital: clinical indications, peripheral smear correlation and diagnostic value. Med J DY Patil Univ 2015;8(4):490-4.

[5] Kibria SG, Islam MDU, Choudhary ASMJ, et al. Prevalence of hematological disorder. A bone marrow study of 177 cases in a private hospital at Faridpur. Faridpur Med Coll J 2010;5(1):11-3.

[6] Shastry SM, Kolte SS. Spectrum of hematological disorders observed in one-hundred and ten consecutive bone marrow aspirations and biopsies. Med J DY Patil University 2012;5(2):118-21.
[7] Anjum MU, Noman N, Shah SH, et al. Spectrum of hematological disorders on bone marrow aspirate examination. Gomal J Med Sci 2014;12:193-6.

[8] Dapus DO, James DG. Dignostic outcome of bone marrow aspiration in a new centre in Nigeria. Glo Adv Res J Med Sci 2012;1(7):166-71.

[9] Jha A, Sayami G, Adhikari RC, et al. Bone marrow examination in cases of pancytopenia. J Nepal Med Assoc 2008;47(169):12-7.

[10] Patel S, Nathani P, Shah N, et al. Diagnostic role of bone marrow aspiration and trephine biopsy in haematological practice. GMJ 2015;70(2):37-41.

[11] Gayathri BN, Rao KS. Pancytopenia: a clinico hematological study. J Lab Physicians 2011;3(1):1520.

[12] Pudasaini S, Prasad KBR, Rauniyar SK, et al. Interpretation of bone marrow aspiration in hematological disorder. Journal of Pathology of Nepal 2012;2:309-12.

[13] Bain BJ. Diagnosis from the blood smear. N Engl J Med 2005;353(5):498-507.

[14] Khan A, Aqeel M, Khan TA, et al. Pattern of hematological diseases in hospitalized paediatric patients based on bone marrow examination. JPMI 2008;22(3):196-200.

[15] Patel J, Popat VC. Spectrum of haematological disorders observed in consecutive 150 cases on bone marrow examination. Int J Res Med 2014;3(2):139-41.

[16] AL-Ghazaly J, Al-Selwi AH, Abdullah M, et al. Pattern of haematological diseases diagnosed by bone marrow examination in Yemen: a developing country experience. Clin Lab Haematol 2006;28(6):376-81.

[17] Kulshrestha R, Sah SP. Pattern of occurrence of leukemia at a teaching hospital in eastern region of Nepal - a six year study. J Nepal Med Assoc 2009;48(173):35-40.

[18] Troussard X, Duchenet V, Cornet E, et al. Haematological malignancies: incidence in BasseNormandie, France for 1997-2004. Rev Epidemiol Sante Publique 2009;57(3):151-8.

[19] Frisch B, Bartl R, Burkhardt R, et al. Histologic criteria for classification and differential diagnosis of chronic myeloprolifereative disorders. Haematologica (Budap) 1984;17(2):209-26. 